\title{
Pim-1 Kinase Phosphorylates Cardiac Troponin I and Regulates Cardiac Myofilament Function
}

\author{
Ni Zhua,b Bing Yia Zhifu Guo ${ }^{a, b} \quad$ Guanxin Zhang ${ }^{a, b}$ Shengdong Huang ${ }^{b}$ \\ Yongwen Qin $^{\mathrm{b}} \quad$ Xianxian Zhao ${ }^{\mathrm{b}} \quad$ Jianxin Sun ${ }^{\mathrm{a}, \mathrm{b}}$
}

${ }^{a}$ Center for Translational Medicine, Thomas Jefferson University, Philadelphia, PA, USA, b Departments of Cardiology and Thoracic Surgery, Changhai Hospital, Second Military Medical University, Shanghai, China

\section{Key Words}

Cardiac troponin I • Pim1 • Phosphorylation • Diabetes • Myofilament function

\begin{abstract}
Background/Aims: Pim-1 is a serine/threonine kinase that is highly expressed in the heart, and exerts potent cardiac protective effects through enhancing survival, proliferation, and regeneration of cardiomyocytes. Its myocardial specific substrates, however, remain unknown. In the present study, we aim to investigate whether Pim-1 modulates myofilament activity through phosphorylation of cardiac troponin I (cTnI), a key component in regulating myofilament function in the heart. Methods: Coimmunoprecipitation and immunofluorescent assays were employed to investigate the interaction of Pim-1 with cTnI in cardiomyocytes. Biochemical, site directed mutagenesis, and mass spectrometric analyses were utilized to identify the phosphorylation sites of Pim1 in cTnI. Myofilament functional assay using skinned cardiac fiber was used to assess the effect of Pim1-mediated phosphorylation on cardiac myofilament activity. Lastly, the functional significance of Pim1-mediated cTnI in heart disease was determined in diabetic mice. Results: We found that Pim-1 specifically interacts with cTnI in cardiomyocytes and this interaction leads to Pim1-mediated cTnI phosphorylation, predominantly at Ser23/24 and Ser150. Furthermore, our functional assay demonstrated that Pim-1 induces a robust phosphorylation of CTnI within the troponin complex, thus leading to a decreased $\mathrm{Ca}^{2+}$ sensitivity. Insulin-like growth factor 1 (IGF-1), a peptide growth factor that has been shown to stimulate myocardial contractility, markedly induces CTnI phosphorylation at Ser23/24 and Ser150 through increasing Pim-1 expression in cardiomyocytes. In a highfat diabetic mice model, the expression of Pim1 in the heart is significantly decreased, which is accompanied by a decreased phosphorylation of cTnI at Ser23/24 and Ser150, further implicating the pathological significance of the Pim1/cTnI axis in the development of diabetic cardiomyopathy. Conclusion: Our results demonstrate that Pim-1 is a novel kinase that phosphorylates cTnI primarily at Ser23/24 and Ser150 in cardiomyocytes, which in turn may modulate myofilament function under a variety of physiological and pathophysiological conditions.




\section{Cellular Physiology Cell Physiol Biochem 2018;45:2174-2186 \\ and Biochemistry Published online: March 15, $2018 \quad \begin{aligned} & \text { DOI: 10.1159/000488161 } 2018 \text { The Author(s). Published by S. Karger AG, Basel } \\ & \text { www.karger.com/cpb }\end{aligned}$ \\ Zhu et al.: Phosphorylation of cTnI by Pim1 Kinase}

\section{Introduction}

Pim-1 is a highly conserved serine/threonine kinase that belongs to the calmodulindependent protein kinase related group and prefers to phosphorylate the consensus sequence $(K / R)-(K / R)-(K / R)-X-(S / T)-X$ [1]. It is originally identified as a cellular oncogene that inhibits apoptosis and promotes proliferation [1]. Recently, accumulating evidence suggests that Pim-1 plays a pivotal role in protecting heart function from ischemia induced damage and cardiac hypertrophy [2,3], as well as protecting mitochondrial integrity in cardiomyocyte [4]. Moreover, Pim-1-engineered cardiac progenitor cells dramatically improve the cardiac function after myocardial infarction [5, 6]. Systemic delivery of human Pim-1 via cardiotropic adeno-associated virus serotype- 9 improves diabetic cardiomyopathy by induction of prosurvival signaling [7]. Furthermore, Pim-1 has been shown to promote cardiomyocyte survival and protect heart muscles from ischemic damage downstream of Akt through regulating expression of anti-apoptotic proteins and calcium channels [8]. Notably, Pim-1 maintains cardiomyocyte contractility by increasing $\mathrm{Ca}^{2+}$ transient amplitude and percentage of cell shortening in isolated cardiomyocyte [8]. However, the molecular mechanisms underlying Pim-1-mediated cardiac contractility still remain unclear.

Cardiac troponin complex has three major components, cardiac troponin I (cTnI), Troponin $\mathrm{T}(\mathrm{TnT})$, and Troponin $\mathrm{C}(\mathrm{TnC})[9,10]$. cTnI is the inhibitory unit that interacts with the major proteins present in the sarcomeric thin filament, including actin, cTnC, $\alpha$-tropomyosin ( $\alpha$-TM), and cTnT [11]. These interactions reveal the pivotal roles of cTnI in regulating heart muscle crossbridge kinetics and contraction in response to changes of intracellular $\mathrm{Ca}^{2+}$ concentrations [12]. Phosphorylation of specific serine and threonine residues on $\mathrm{cTnI}$ by several different kinases represents a major physiological mechanism for alteration of myofilament properties. For example, cAMP-dependent protein kinase (PKA) mediates phosphorylation of the two serine residues (Ser-23/24) in the unique N-terminal domain of $\mathrm{CTnI}$, leading to a reduction in myofilament $\mathrm{Ca}^{2+}$ sensitivity and an increase in crossbridge cycling rate by reducing the $\mathrm{Ca}^{2+}$-binding affinity of cTnC [13]. Likewise, PKD1 phosphorylates cTnI at Ser-23/24, resulting in desensitization of the myofilament response to $\mathrm{Ca}^{2+}$ as well as an increase in cross-bridge kinetics $[14,15]$. Another important protein kinase family, protein kinase C (PKC) is found to phosphorylate cTnI at Ser-23/24, Ser-43/45, and Thr144 residues [16]. Phosphorylation of the Ser-43/45 sites depresses the maximum tension and crossbridge kinetics, which is in contrast to phosphorylation of Ser-23/24 [17]. Moreover, the effect of phosphorylation at Ser-43/45/Thr144 dominates the effects of phosphorylation at Ser-23/24 [18]. Other kinases such as P21-activated kinases (PAK) have been found to cause phosphorylation of cTnI at Ser-149, which results in an increase in myofilament $\mathrm{Ca}^{2+}$ sensitivity [19]. More recently, 5'-AMP kinase (AMPK) has been shown to induce an increase in $\mathrm{Ca}^{2+}$ responsiveness of the myofilaments and blunt PKA-dependent function through phosphorylation of Ser-150 of cTnI [20-22]. Importantly, by using mass spectrometric (MS) approaches, Zhang et al. demonstrated that there is a depression in phosphorylation at cTnI-Ser23/24 but an increase in phosphorylation of cTnI-Ser43/45 in human ischemic and dilated cardiomyopathy [23]. Thus, alteration of cTnI phosphorylation levels has a great clinical relevance that may shed light on the discovery of novel therapeutic targets of heart failure.

Pim-1 is implicated in regulating cardiomyocyte contractility and calcium transient, the role of Pim-1 in modulating cardiac myofilament activity, however, remains largely unknown [8]. In the present study, we for the first time identified Pim-1 as a novel kinase that specifically interacts with cTnI and causes cTnI phosphorylation at Ser23/24 and Ser150, thus leading to a reduced $\mathrm{Ca}^{2+}$ sensitivity of contractile regulation. Furthermore, we demonstrated that IGF-1, a peptide growth factor that has been shown to stimulate myocardial contractility and protects cardiac injury [24, 25], significantly induces cTnI phosphorylation at Ser23/24 and Ser150 in a Pim-1 dependent manner in cardiomyocytes. Collectively, these results suggest that cTnI phosphorylation by Pim-1 may represent a novel mechanism underlying the Pim1-mediated protective effects in the heart. 


\section{Cellular Physiology Cell Physiol Biochem 2018;45:2174-2186

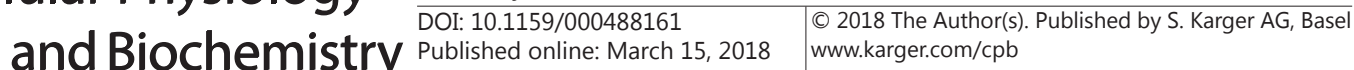 Zhu et al.: Phosphorylation of cTnI by Pim1 Kinase}

\section{Materials and Methods}

\section{Cell culture}

Human embryonic kidney cells HEK293T and Ad293 cells (ATCC) were cultured in Dulbecco's modified Eagle's medium (DMEM) supplemented with 10\% FBS (GIBCO), 1\% penicillin/streptomycin (GIBCO) in a humidified atmosphere of $5 \% \mathrm{CO}_{2}$ at $37^{\circ} \mathrm{C}$.

\section{Animal model of diabetes}

Wild-type (WT) and db/db mice on C57BLK6/J background were obtained from Jackson Laboratory. Animals were fed either regular chow diet or high fat diet (HF) from 8 week old to 16 week old as described previously [26]. Mice were sacrificed by inhalation of $\mathrm{CO}_{2}$ for the collection of the heart. This study was reviewed and approved by the Institutional Animal Care and Use Committee at Thomas Jefferson University.

\section{Isolation of adult rat ventricular myocytes}

Ventricular myocytes were isolated from the hearts of adult male Sprague-Dawley rats by collagenasebased enzymatic digestion, as described previously [15]. In brief, hearts were excised and perfused for 5 min with modified HEPES-Krebs solution $\left(\mathrm{pH} 7.3\right.$ at $37^{\circ} \mathrm{C}$ ) containing (in mmol/L) $\mathrm{NaCl} 130, \mathrm{MgCl}_{2} 4.5$, $\mathrm{NaH}_{2} \mathrm{PO}_{4} 0.4, \mathrm{CaCl}_{2} 0.75$, HEPES 4.2, taurine 20, creatine 10 and glucose 10 . The buffer was saturated with $95 \% \mathrm{O}_{2} / 5 \% \mathrm{CO}_{2}\left(\mathrm{pH} 7.4,37^{\circ} \mathrm{C}\right)$. Hearts were then consecutively retrogradely perfused with $\mathrm{Ca}^{2+}$-free HEPESKrebs solution containing $100 \mu \mathrm{mol} / \mathrm{L}$ EGTA (4 min) and HEPES-Krebs solution containing $100 \mu \mathrm{mol} / \mathrm{L}$ $\mathrm{CaCl}_{2}$ and $1 \mathrm{mg} / \mathrm{mL}$ type II collagenase (Worthington, Lakewood, USA). Hearts were then removed from the perfusion apparatus, the ventricles cut into small pieces, and isolated myocytes were separated from undigested ventricular tissue by filtering through nylon gauze, and the latter was incubated in $30 \mathrm{~mL}$ of the collagenase solution for a further $8 \mathrm{~min}$. This step was repeated, thereby generating three isolated myocyte fractions. In each fraction, myocytes were allowed to settle into a loose pellet and the supernatant was removed and replaced with HEPES-Krebs solution containing $1 \% \mathrm{BSA}$ and $500 \mu \mathrm{mol} / \mathrm{L} \mathrm{CaCl}{ }_{2}$. Myocytes were again allowed to settle, the supernatant removed and the cells finally pooled and resuspended in 30 $\mathrm{mL}$ of HEPES-Krebs solution containing $1 \mathrm{mmol} / \mathrm{L} \mathrm{CaCl}_{2}$. The pooled isolated myocytes were pelleted by brief centrifugation at $50 \mathrm{~g}$ and washed at room temperature.

\section{Co-immunoprecipitation of cTnI and Pim-1 in HEK293T cells and heart tissues}

HEK293T cells were transiently transfected with Flag-tagged cTnI and Myc-tagged Pim-1 expression plasmids using PEI following our standard protocol for 48 hours. HEK293T cells or rat heart tissues were lysed or homogenized in a buffer containing $50 \mathrm{mM}$ Tris/HCl (pH 8.0), 1\% Nonidet P40, $150 \mathrm{mM} \mathrm{NaCl}$ and protease inhibitors. Co-immunoprecipitation of cTnI and Pim-1 was performed as described previously [27]. The following antibodies and beads were used for detection and immunoprecipitation: rat polyclonal anti-Myc antibody (Genescript), mouse monoclonal anti-FLAG antibody (Genescript), rabbit monoclonal anti-Pim1 antibody (Santa Cruz) and rabbit monoclonal anti-TnI antibody (Cell Signaling), anti-c-Mycagarose affinity gel (Sigma) and anti-FLAG M2-agarose (Sigma).

\section{Immunoblotting}

Cell lysates were made using RIPA buffer (Thermo Scientific) containing $25 \mathrm{mM}$ Tris-HCl pH 7.6, 150 $\mathrm{mM} \mathrm{NaCl}, 1 \% \mathrm{NP}-40,1 \%$ sodium deoxycholate, $0.1 \%$ SDS and proteinase inhibitor cocktail containing $2 \mathrm{mM}$ PMSF, $20 \mu \mathrm{g} / \mathrm{mL}$ aprotinin, $10 \mu \mathrm{g} / \mathrm{mL}$ leupeptin. After $1 \mathrm{~h}$ extraction with rocking at $4^{\circ} \mathrm{C}$, insoluble material was removed by centrifugation. Supernatants were resolved by SDS-PAGE, and transferred to nitrocellulose membranes (Bio-Rad), which were blocked with $5 \%$ non-fat milk in PBS with $0.1 \%$ Tween 20 (PBS/T) and then incubated with diluted antibodies overnight at $4{ }^{\circ} \mathrm{C}$ with agitation. After washing with PBS/T for three times, membranes were incubated with appropriate secondary antibodies (Thermo Scientific). Blots were visualized on an Odyssey Imaging System (LI-COR) as we described previously [28]. The following antibodies were used for detecting phosphorylated TnI: anti-phospho-Troponin I (Cardiac) (Ser23/24) antibody (Cell Signaling), Troponin I Type 3 (cardiac) [p-Ser150] Antibody (Ser150) antibody (Novus).

\section{Immunofluorescent staining}

The myocytes cultured on the laminin-coated glass coverslips were fixed with $4 \%$ paraformaldehyde for 10 min, washed three times in PBS, and then permeabilized with 0.25\%Triton-X100 for 15 min. Following a 


\section{Cellular Physiology Cell Physiol Biochem 2018;45:2174-2186 \begin{tabular}{l|l} 
and Biochemistry Published onine:March 15, 2018 & $\begin{array}{l}\text { (c) } 2018 \text { The Author(s). Published by S. Karger AG, Basel } \\
\text { www.karger.com/cpb }\end{array}$
\end{tabular} \\ Zhu et al.: Phosphorylation of cTnI by Pim1 Kinase}

blocking step with $10 \%$ of goat serum in PBS for 60 min, the cardiomyocyte were co-immunostained with a rabbit monoclonal primary antibody against cTnI (1:200, Cell Signaling) and a mouse monoclonal antibody against Pim-1 (1:200, Santa Cruz) for overnight at $4^{\circ} \mathrm{C}$. After washing three times in PBS for $10 \mathrm{~min}$, cells were stained with TRITC-conjugated anti-rabbit IgG and FITC-conjugated anti-mouse IgG second antibodies at 1:250 (Invitrogen, USA), respectively, at $37^{\circ} \mathrm{C}$ for $2 \mathrm{~h}$ and then were rinsed three times with PBS. Cell nuclei were stained with DRAQ5. The stained cells were observed by laser-scanning confocal microscopy (Leica, Heidelberg, Germany).

\section{In vitro phosphorylation assays}

Recombinant human cTnI, human troponin complex (Prospec, East Brunswick, NJ), skinned myocyte were incubated with active recombinant Pim-1 (EMD Millipore) and $100 \mu \mathrm{mol} / \mathrm{L}^{32} \mathrm{P}-\mathrm{ATP}$ (PerkinElmer) in a kinase assay buffer containing (in mmol/L) Tris-HCl (pH 7.5) 25, beta-glycerophosphate 5, dithiothreitol (DTT) $2, \mathrm{Na}_{3} \mathrm{VO}_{4} 0.1, \mathrm{MgCl}_{2} 10$ for up to $120 \mathrm{~min}$ at $37^{\circ} \mathrm{C}$ as we described previously [28]. The reaction was terminated by the addition of 0.5 volumes of $3 \times$ Laemmli sample buffer and incubated at $95{ }^{\circ} \mathrm{C}$ for $5 \mathrm{~min}$, and then resolved by SDS/PAGE (12\% gels) and autoradiography. For western blot analysis, recombinant cTnI or its mutants was phosphorylated by incubating with active Pim-1 in the presence of non-radiolabelled ATP $(500 \mu \mathrm{mol} / \mathrm{L})$.

\section{Identification of phosphorylation sites by mass spectrometry}

Peptides contained Ser23/24 and Ser150 (APIRRRSSNYRA and TLRRVRISADAM) were synthesized by Genscript. Peptides were incubated with active Pim-1 in the presence of non-radiolabelled ATP (500 $\mu \mathrm{mol} / \mathrm{L}$ ) at $30{ }^{\circ} \mathrm{C}$ for $60 \mathrm{~min}$. For peptide mass spectrometry analysis of the tryptic digestion products, $50 \mu \mathrm{L}$ of the solution was analyzed by LC-MS, using an HPLC system (Series 1100, Agilent Technologies) coupled to an electrospray ionization mass spectrometer (Finnigan LCQ Advantage MAX, Thermo Electron Corp.). For HPLC separation of the peptides, a CC 250/4 Nucleosil 100-5 C18 Nautilus column (Macherey-Nagel GmbH) was used, with a linear gradient over 60 min of 0-65\% solution B in solution A (solution A, $0.1 \%$ formic acid in water; solution B, $0.1 \%$ formic acid in acetonitrile). Mass spectra were analyzed using Finnigan Xcalibur software (Thermo Electron Corp.) and the peptide masses assigned, using ExPASy software.

\section{Expression of cTnI mutants and immunoprecipitation kinase assay}

Mutants ofFlag-taggedcTnI plasmids(Ser23/24 $\rightarrow$ Ala23/24,TCC/TCC $\rightarrow$ GCC/GCC;Ser42/44 $\rightarrow$ Ala42/44, TCC/TCG $\rightarrow$ GCC/GCG; Thr143 $\rightarrow$ Ala143, ACC $\rightarrow$ GCC; Ser150 $\rightarrow$ Ala150, TCT $\rightarrow$ GCT) were generated using QuickChange II kit as described by the manufacturer (Agilent). Wild type or mutated plasmids were transiently transfected into HEK293T cells and lysed with IP lysis buffer. Immunoprecipitation was performed as described previously [27]. In brief, cell lysates were incubated with anti-Flag M2-agarose (Sigma) overnight at $4^{\circ} \mathrm{C}$ with rotation. Agarose beads were centrifuged for $30 \mathrm{sec}$ at $4^{\circ} \mathrm{C}$, followed by three times washing with $500 \mu \mathrm{l}$ of $1 \mathrm{X}$ kinase buffer. The beads pellets were resuspended in $20 \mu \mathrm{l} 1 \mathrm{X}$ kinase buffer supplemented with $100 \mu \mathrm{mol} / \mathrm{L}^{32} \mathrm{P}$-ATP (PerkinElmer) and active Pim-1 protein and then incubated $60 \mathrm{~min}$ at $30^{\circ} \mathrm{C}$. The reaction was terminated by the addition of 0.5 volumes of $3 \times$ Laemmli sample buffer and incubated at $95{ }^{\circ} \mathrm{C}$ for $5 \mathrm{~min}$, and was then resolved by SDS/PAGE (12\% gels) and autoradiography.

\section{Skinned myocyte preparation}

Skinned myocyte was prepared as described previously with modifications [21]. Hearts from SpragueDawley rats were excised and immersed in ice-cold relaxing solution, containing (in mmol/L) EGTA 10, 2-[N,N-Bis(2-hydroxyethyl)amino] ethanesulfonic acid (BES) 100, potassium proprionate 55, ATP 5, creatine phosphate 10 , free $\mathrm{Mg}^{2+} 1$, and protease inhibitor. The myocardial tissue was homogenized in a Waring blender ( $10 \mathrm{~s}$ in ice cold relaxing solution) and, following centrifugation (1400 rpm, $1 \mathrm{~min}$ ), the myocyte pellet was re-suspended in Triton X-100 (1\% v/v in relaxing solution) for $10 \mathrm{~min}$, to disrupt lipid membranes. Following two further cycles of similar centrifugation and re-suspension, the myocyte pellet was washed, re-suspended and kept in ice-cold relaxing solution, until used for in vitro phosphorylation assays or mechanical measurements.

Functional studies in skinned myocyte fragments

Rat skinned cardiac muscle fibers were pre-incubated with or without $0.1 \mathrm{mg} / \mathrm{ml}$ Pim 1 in a relaxing solution for $30 \mathrm{~min}$. Force measurement was performed as previously described [14]. For mechanical 


\section{Cellular Physiology Cell Physiol Biochem 2018;45:2174-2186 \begin{tabular}{l|l} 
DOI: 10.1159/000488161 & $\begin{array}{l}\text { O 2018 The Author(s). Published by S. Karger AG, Basel } \\
\text { www.karger.com/cpb }\end{array}$
\end{tabular} \\ Zhu et al.: Phosphorylation of cTnI by Pim1 Kinase}

measurements, myocyte fragments were clamped to a sensitive force transducer (Model 403A, $200 \mathrm{mV}$ / mg, Cambridge Technology, Inc.) and a high-speed length controller (Model 308B, Aurora Scientific, Inc.) at either end. All mechanical experiments were performed at $18{ }^{\circ} \mathrm{C}$. Sarcomere length was acquired (240 $\mathrm{Hz}$ CCD camera) and analyzed using commercial software (IonOptix Corp.). The sarcomere length was set to $\sim 2.0 \mu \mathrm{m}$ in relaxing solution for all functional measurements. Solution changes were made using a fast stepper motor attached to 2 parallel capillary tubes (Model SF-77B Perfusion Fast-Step, Warner Instrument Corp.). pClamp software (Axon Instruments) was used to trigger the stepper motor for solution changes or to impose rapid length changes on the myocyte fragment. Force and length signals were recorded on a computer using a 12-bit analog/digital board, sampling at $2 \mathrm{kHz}$. Skinned myocytes were activated in solutions $(\mathrm{pH} 7.0)$ containing a $\mathrm{Ca}^{2+}$ concentration ranging between $10^{-9}$ (pCa 9.0; relaxing solution, composition as given above) and $10^{-4.5} \mathrm{~mol} / \mathrm{L}$ (pCa 4.5; maximal $\mathrm{Ca}^{2+}$ activating solution), to measure the $\mathrm{Ca}^{2+}$ sensitivity of myofilaments.

\section{Statistical analyses}

Data are expressed as means \pm SE. The statistical significance of differences was assessed by Student's $t$-test or analysis of variance (ANOVA) with Bonferroni's post hoc test, as appropriate; a value of $\mathrm{P}<0.05$ was considered statistically significant.

\section{Results}

\section{Interaction of Pim-1 with cTnI}

To elucidate the mechanism underlying the regulation of cardiac contractility by Pim-1 $[8,29]$, we attempted to investigate whether the cardio-protective kinase Pim-1 interacts with cTnI. In this regard, Myc-tagged human Pim-1 and Flag-tagged human cTnI plasmids were co-transfected into HEK293T cells, co-immunoprecipitation was then performed. As shown in Fig. 1A, immunoprecipitation of Myc-tagged Pim-1 led to co-precipitation of FLAG-tagged cTnI. Similarly, immunoprecipitation of Flagtagged cTnI resulted in the co-immunoprecipitation of Myc-tagged Pim-1 (Fig. 1A). To determine whether there is an endogenous interaction of cTnI and Pim-1 in cardiomyocytes, we performed co-immunoprecipitation with anti-Pim-1 antibody using mouse heart lysates. As shown in Fig. 1B, cTnI co-precipitated with the antiPim-1 antibody, but not with the nonimmune IgG. To investigate the intracellular localization of this interaction, we performed immunofluorescent staining in adult mouse cardiomyocytes. Immunofluorescent microscopy showed a strong colocalization of Pim-1 and cTnI in the sarcomere of cardiac cells (Fig. 1C). Together, these results indicate that Pim-1 interacts with cTnI in cardiomyocytes under physiological conditions.

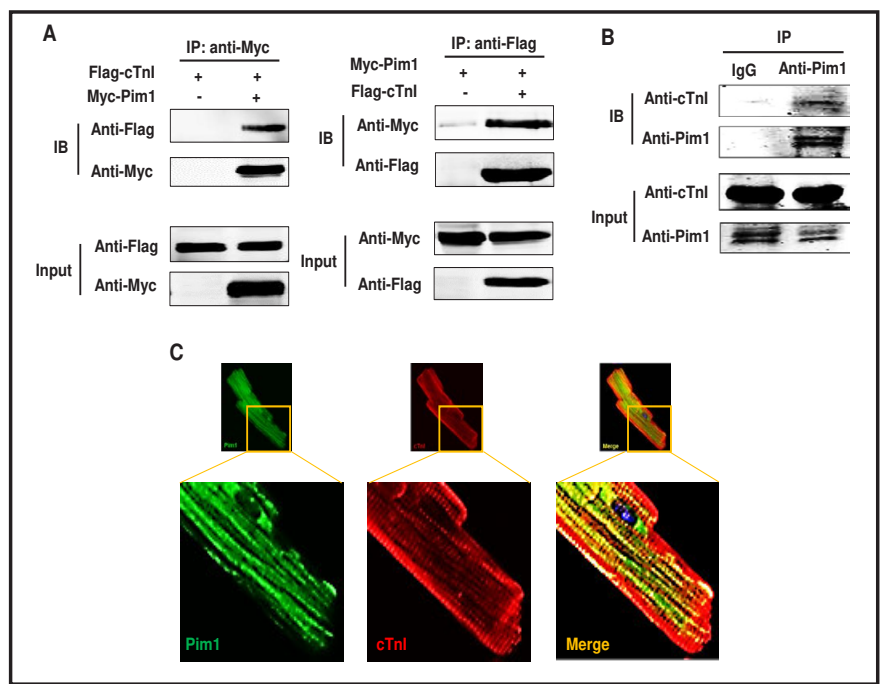

Fig. 1. Interaction of Pim-1 with cTnI. (A). HEK293T cells were co-transfected with Flag-cTnI and Myc-Pim-1. Co-immunprecipitation were performed by using anti-Flag or anti-Myc antibodies and then analyzed by western blot. (B). Adult mouse heart tissue samples were extracted and immunoprecipitated with either anti-Pim-1 antibody or control IgG and then analyzed by western blot. (C) Fixed adult mouse cardiomyocyte were stained with antiPim-1 and anti-cTnI antibodies and then processed for fluorescent staining analysis. 
Pim-1 phosphorylates cTnI primarily at serine 23/24 and serine 150

Since Pim-1 is a serine/ threonine kinase, the interaction of Pim1 with cTnI prompted us to investigate whether $\mathrm{cTnI}$ is a good substrate of Pim-1. To test this hypothesis, in vitro phosphorylation assays were carried out using purified recombinant human cTnI as substrate, which was incubated with active Pim-1 in the presence of $\left[\gamma^{-32} \mathrm{P}\right]$ ATP. As shown in Fig. 2A and 2B, incubation of recombinant Pim-1 with cTnI resulted in a robust phosphorylation of cTnI in a time and dose-dependent manner. To determine the phosphorylation kinetics of troponin complex by Pim-1, the time course of Pim1 -induced phosphorylation of the reconstituted troponin (Tn) complex was determined in an in vitro kinase assay. Interestingly, Pim-1 phosphorylates cTnI in the troponin complex in a time-dependent manner, while TnT was also phosphorylated by Pim-1 in the Tn complex (Fig. 2C). Taken together, these results suggest that cTnI is a good substrate of Pim-1 kinase.

Because Pim-1 preferentially phosphorylates the consensus sequence (K/R)(K/R)-(K/R)-X-(S/T)-X [30], and phosphorylation of several serine/threonine sites in cTnI has been reported to play important roles in regulation of cardiac contraction/relaxation. We attempted to map the Pim1induced phosphorylation sites in cTnI by a site-directed mutagenesis of Ser (S) to Ala (A) [28]. Mammalian expression plasmids bearing Flag-tagged S23/24A, S42/44A, T143A and S150A mutants were constructed and then transfected into HEK293T cells. 48 hours after

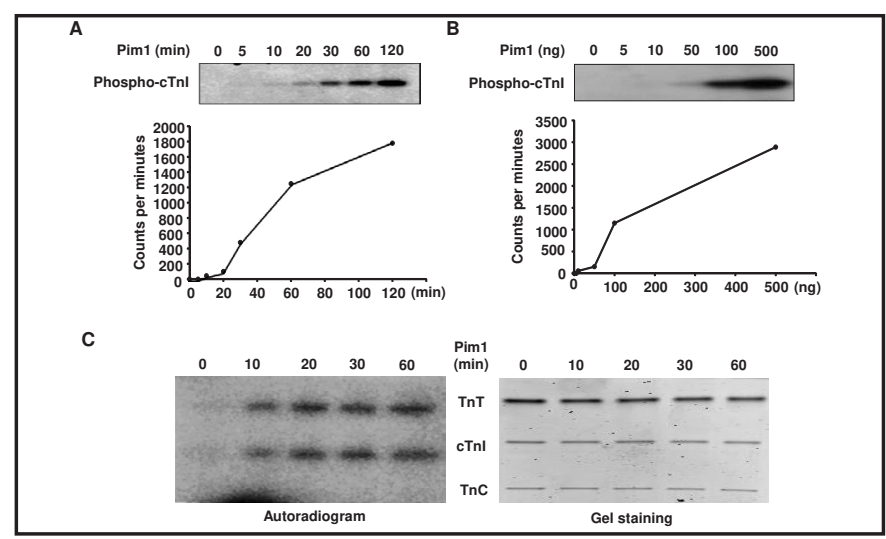

Fig. 2. cTnI is phosphorylated by Pim- 1 at Ser-23/24 and Ser-150. Recombinant cTnI was incubated with active Pim-1 in the presence of $[\gamma$-32P]ATP for different times (A) or different doses (B). Phosphorylation was detected by autoradiography and cpm was counted. (C), The Tn complex was incubated with $0.5 \mu \mathrm{g}$ of active Pim-1 for different time points as indicated in the presence of $[\gamma$ -32P]ATP in an in vitro phosphorylation assay. Both the autoradiograph (left panel) and the Coomassie-stained gel (right panel) are shown.

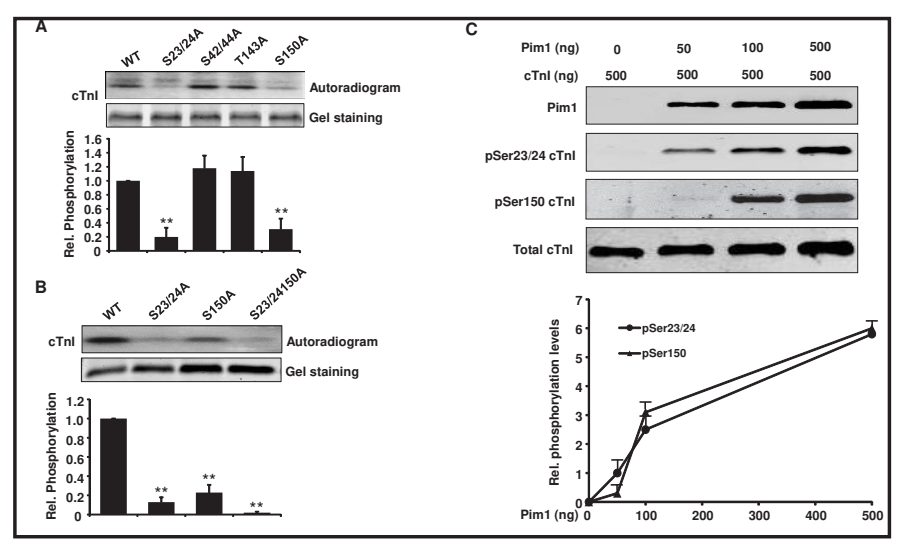

Fig. 3. Identification of Pim-1-induced phosphorylation sites in cTnI. (A), Autoradiograph of 12\% SDS-polyacrylamide gel showing the phosphorylation levels of wild-type and different mutants of cTnI by Pim-1. Expression vectors bearing WT and different mutants of cTnI were transfected into HEK293 cells. 48hr after transfection, overexpressed protein was immunoprecipitated by anti-Flag antibody and then subjected to an in vitro kinase in the presence of active Pim- 1 and $[\gamma-32 \mathrm{P}]$ ATP. ${ }^{* *} \mathrm{P}<0.01$ vs WT group. (B). Autoradiograph of $12 \%$ SDS-polyacrylamide gel showing Pim-1-induced phosphorylation levels of human cTnI containing either wild-type or combined mutation of cTnI in an in vitro kinase assay. Expression vectors bearing WT and various mutants of cTnI were transfected into HEK293 cells. 48hr after transfection, overexpressed protein was immunoprecipitated by anti-Flag antibody and then subjected to an in vitro kinase in the presence of active Pim- 1 and $[\gamma-32 \mathrm{P}]$ ATP. ** $\mathrm{P}<0.01$ vs WT group. (C). cTnI was incubated with active Pim-1 in the presence of ATP and Pim-1, phospho-ser23/24 and ser-150 was detected by western blot and quantitated by densitometric analysis. 
transfection, overexpressed proteins were immunoprecipitated by anti-Flag antibody and then used for an in vitro kinase assay in the presence of active Pim-1 and $\left[\gamma^{-32} \mathrm{P}\right]-\mathrm{ATP}$. As shown in Fig. 3A, TnI S23/24A mutant significantly abolished Pim-1-mediated cTnI phosphorylation by approximately $80 \%$, whereas S150A mutant caused a $\sim 60$ $\%$ reduction in cTnI phosphorylation, suggesting that Pim-1 phosphorylates cTnI primarily at Ser-23/24 and Ser-150. Furthermore, a S23/24/150A triple mu-

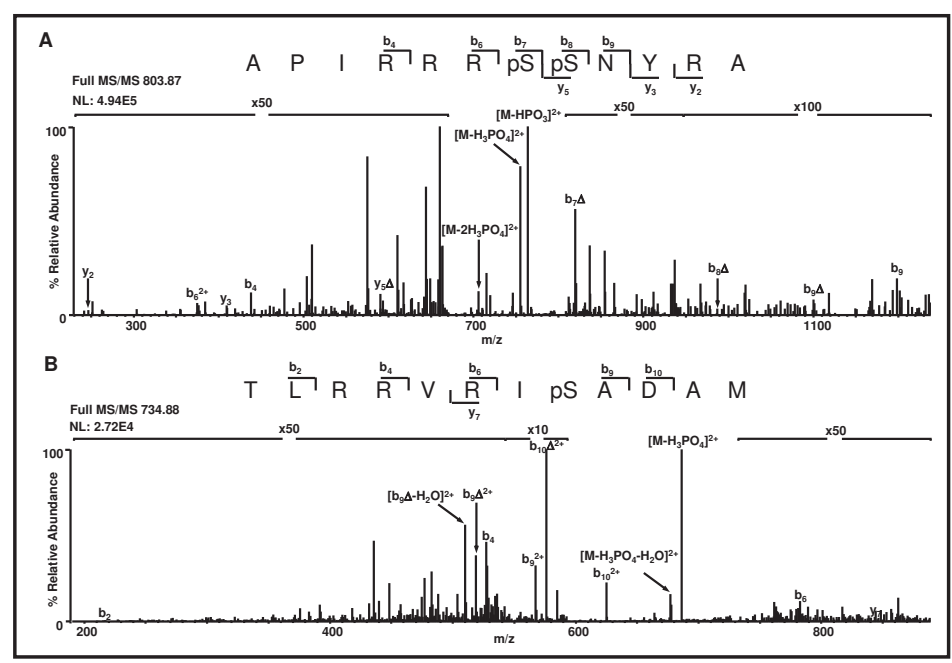

Fig. 4. MS/MS analysis of synthetic peptides phosphorylated by Pim-1. (A). Spectrum of phosphorylated peptide containing Ser23/24 of cTnI. (B). Spectrum of phosphorylated peptide containing Ser150 of cTnI. tant was generated and the mutant protein was overexpressed and immunoprecipitated for an in vitro phosphorylation assay. Notably, triple mutant of S23/24/150A almost completely abolished Pim1-induced cTnI phosphorylation (Fig. 3B). Moreover, Pim-1 induced in vitro phosphorylation of cTnI was detected by western blot using anti-phosphoSer/23/24 and phosphor-Ser150 specific antibodies. As shown in Fig. 3C, both Ser-23/24 and Ser-150 of cTnI were robustly phosphorylated by Pim1 in a dose-dependent manner.

\section{Verification of the phosphorylation} sites by MALDI-TOF-MS

To further confirm the Pim-1-induced phosphorylation sites in cTnI, two peptides derived from cTnI spanning the potential phosphorylation residues of Ser23/24 and Ser150 were synthesized, respectively, and then treated with active pim 1 protein. Phosphorylation of peptides was analyzed by the high resolution mass spectrometry. As shown in Fig. 4A and 4B, both peptides were efficiently phosphory-

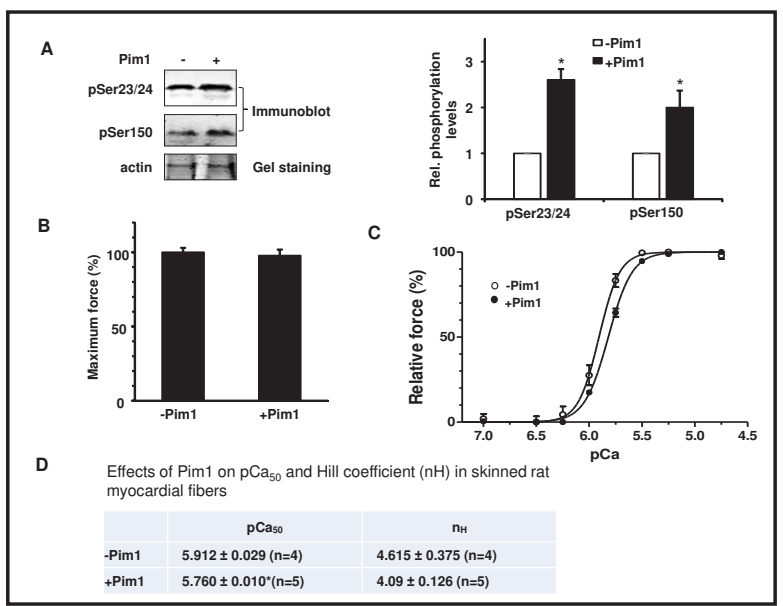

Fig. 5. Effects of Pim-1-mediated phosphorylation on $\mathrm{Ca}^{2+}$ sensitive tension development in skinned myocytes. (A). Pim-1-mediated cTnI phosphorylation in skinned myocyte preparations, as detected by western blot and quantitated by densitometric analysis. Equal protein loading is indicated by actin on coomassie-stained gels. ${ }^{* *} \mathrm{P}<0.01$ vs non-treatment group. (B). Relative maximum force development by skinned myocytes in the presence or absence of Pim-1 incubation. ( $n=5$ per group). (C). Tension-pCa relationship under control and after Pim-1-mediated phosphorylation in the presence of solutions at pCa 9.0 to 4.5 ( $n=5$ per group). lated at Ser23/24 and Ser150 by Pim1, further indicating that Pim1 could potentially phosphorylate cTnI at Ser23/24 and Ser150.

\section{Pim-1 regulates cardiac myofilament function}

To determine the effect of Pim1-induced cTnI phosphorylation on cardiac myofilament activity, we first investigated whether Pim1 phosphorylates cTnI Ser23/24 and Ser150 


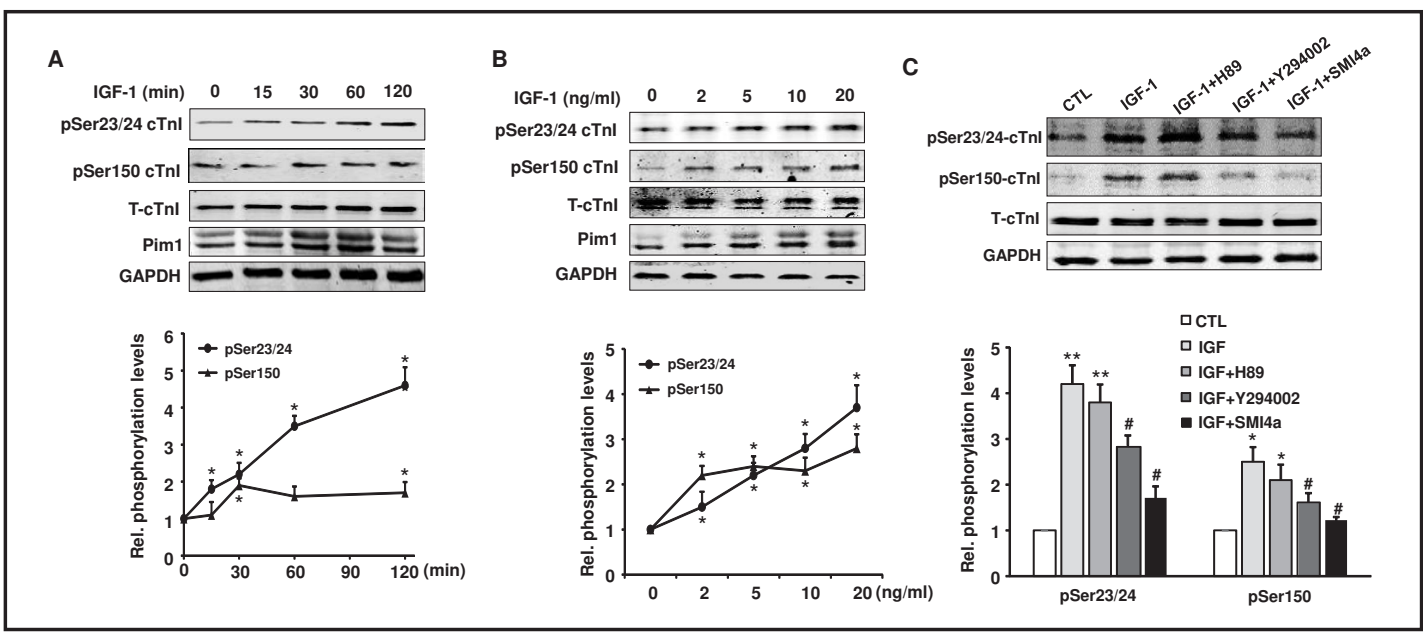

Fig. 6. Pim-1 is involved in IGF-1-induced cTnI phosphorylation in cardiomyocytes. (A). Rat ventricular cardiomyocytes were stimulated with IGF-1 (20 ng/ml) at different time points (A) and doses for $60 \mathrm{~min}$ (B), phosphorylation levels of cTnI at Ser23/24 and Ser150, total cTnI, and Pim-1 were detected by western blot and quantitated by densitometric analysis. ${ }^{*} \mathrm{P}<0.05$; ${ }^{* *} \mathrm{P}<0.01$ vs basal level. $\mathrm{n}=3$. (C). Cardiomyocytes were treated with SMI-4a (10 $\mu \mathrm{M})$, LY294002 (30 $\mu \mathrm{M})$ or H89 $(10 \mu \mathrm{M})$ for $1 \mathrm{hr}$, followed by stimulating with IGF-1 (20 ng/ml) for $2 \mathrm{hr}$, phosphorylation levels of cTnI at Ser23/24 and Ser150, total cTnI, and Pim-1 were detected by western blot and quantitated by densitometric analysis. ${ }^{*} \mathrm{P}<0.05$ vs. CTL. ${ }^{*} \mathrm{P}<0.05$ vs. IGF-1 treated group. SMI-4a, Pim-1 inhibitor; LY294002, PI3K inhibitor; H89, PKA inhibitor.

residues in skinned fibers from the adult rat left ventricle. As expected, there was a significant increase in the phosphorylation of Ser23/24 and Ser150 after a 60-minute exposure of the skinned fiber preparation to active Pim1, indicating that cTnI is a natural substrate of Pim1 and Pim1 may regulate $\mathrm{Ca}^{2+}$ sensitivity in skinned myocardial preparations (Fig. 5A). Then, we determined whether Pim-1-mediated cTnI phosphorylation affects myofilament contractility and calcium selectivity in skinned myocytes from the adult rat left ventricle. Although there was no significant difference between the control and Pim1-treated groups in maximum force and Hill coefficient $\left(\mathrm{n}_{\mathrm{H}}\right)$ (Fig. 5B), Pim1-mediated phosphorylation of cTnI significantly reduced the $\mathrm{Ca}^{2+}$ sensitivity of skinned myocardial fibers, resulting in a rightward shift of the force-pCa curve (Fig. 5C). As shown in Fig. 5D, pCa at 50\% maximal tension (pCa50) was $5.912 \pm 0.029$ in the control group $(n=4)$ and $5.760 \pm 0.010$ in the Pim1-treated group $(\mathrm{n}=5 ; P<0.05)$, suggesting that there was a reduction of $\mathrm{Ca}^{2+}$ sensitivity of Pim1-modified skinned fiber preparations.

\section{IGF-1 phosphorylates cTnI through inducing expression of Pim-1 in cardiomyocytes}

Insulin like growth factor 1 (IGF-1) has been shown to stimulate cardiac growth and contractility and exert protective effects in the heart, although the mechanism of this effect still remains elusive [25]. Interestingly, IGF has recently been shown to potently induce Pim1 expression in the heart [8], which prompted us to speculate that IGF-1 may regulate cardiomyocyte contractility via Pim-1-induced cTnI phosphorylation. To test this hypothesis, rat ventricle cardiomyocytes were stimulated with IGF-1 and phosphorylation of cTnI at Ser-23/24 and Ser-150 were then determined by western blot. Indeed, consistent with a previous report [8], IGF-1 treatment of cardiomyocytes markedly induces Pim-1 expression, which parallels the increased phosphorylation of cTnI at Ser23/24 and Ser150 in cardiomyocytes (Fig. 6A and 6B). To further determine the molecular signaling pathway (s) involved in IGF-1-induced cTnI phosphorylation, several pharmacological inhibitors of protein kinases were utilized. As shown in Fig. 6C, pretreatment of cardiomyocytes with PKA inhibitor H89 barely affected IGF-I-induced cTnI phosphorylation, while inhibition of AKT pathway with LY294002 partially, but significantly, blocked IGF-1-induced cTnI phosphorylation. Importantly, pretreatment of cardiomyocytes with SMI-4a, a Pim-1 specific KARGER 
Fig. 7. Phosphorylation of cTnI and expression of Pim-1 are decreased in the heart of diabetic mice. (A). Hearts were harvested from control C57BLKS/J mice (WT) and $\mathrm{db} / \mathrm{db}$ mice. cTnI phosphorylation and

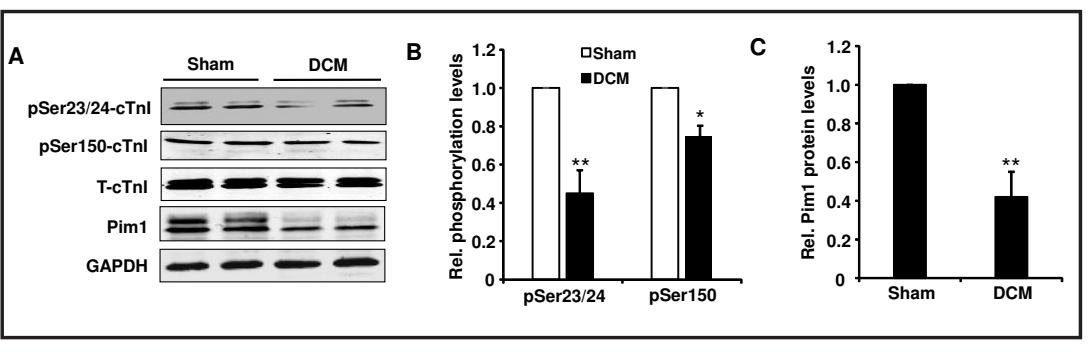
expression of Pim-1 were analysed by western blot. Phosphorylation of cTnI (B) and expression of Pim-1 (C) were quantitated by densitometric analysis. ${ }^{*} \mathrm{P}<0.05$; ${ }^{* *} \mathrm{P}<0.01$ vs. with WT mice (Student's t-test), $\mathrm{n}=6$.

inhibitor [30], almost completely blocked IGF-1-induced cTnI phosphorylation, suggesting that IGF-1-induced cTnI phosphorylation in cardiomyocytes is Pim-1 dependent.

\section{Implication of the Pim1/cTnI axis in diabetic cardiomyopathy}

Our previous studies have shown that the expression of Pim-1 is dramatically downregulated in diabetic mouse heart tissues [30]. Furthermore, the cardiac contractility and cTnI phosphorylation have been shown to be significantly reduced in diabetic hearts $[31,32]$. To further substantiate the pathophysiological significance of Pim-1-induced cTnI phosphorylation, we determined whether Pim-1 expression is correlated with cTnI phosphorylation in vivo. In this regard, Pim1 expression and cTnI phosphorylation levels were analyzed in heart homogenates from the diabetic $d b / d b$ mice fed with a HF and their normal controls by western blot analysis. As shown in Fig. 7A and 7B, consistent with previous reports $[30,33]$, the expression of Pim-1 was significantly decreased in the diabetic hearts. Likewise, the phosphorylation levels of cTnI at Ser23/24 were markedly reduced by approximately $60 \%$, while the phosphorylation of cTnI at Ser150 was slightly, but statistically significantly, decreased by approximately $25 \%$, as compared to their normal controls (Fig. 7C). Together, these results suggest that decreased Pim 1 expression with a resultant reduction of cTnI phosphorylation in the heart might play important roles in the development of diabetic cardiomyopathy.

\section{Discussion}

Covalent modification of cTnI by kinase-mediated phosphorylation is an important mechanism in the regulation of thin filament function and thereby the cardiac contractile phenotype $[11,12]$. Furthermore, altered phosphorylation of cTnI and other myofilament proteins have been shown to contribute causally to the cardiac dysfunction in the transition from compensated hypertrophy to heart failure [23]. Thus far, several protein kinases, including PKA, PKC, AMPK, and PKD, have been shown to phosphorylate cTnI and regulate myofilament activity [34, 35]. In the present study, we provide the compelling evidence implicating Pim-1 as a novel protein kinase that specifically interacts with and phosphorylates cTnI at Ser23/24 and Ser150 in the heart. Indeed, Pim1 and cTnI were found to colocalize in adult cardiomyocytes. The functional consequence of this interaction was demonstrated by the ability of Pim1 to induce cTnI phosphorylation and reduce myofilament calcium sensitivity. Indeed, IGF-1, a cardiac protective hormone that has been shown to increase cardiac contractility, increases Pim-1 expression and cTnI phosphorylation cardiac cells. These results suggest that the phosphorylation of cTnI by Pim1 may be an important determinant of cardiac myofilament activity.

Recently the pathophysiological roles of Pim-1 in the heart have received a significant attention. Both loss- and gain-of-function studies have implicated Pim-1 as an essential kinase in the regulation of cardiomyocyte survival, calcium dynamics, cardiac contractility, and mitochondrial function in cardiomyocytes. For instance, cardiac specific overexpression 


\section{Cellular Physiology Cell Physiol Biochem 2018;45:2174-2186

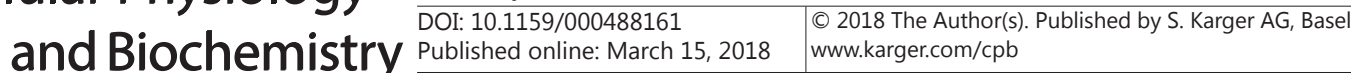 \\ Zhu et al.: Phosphorylation of cTnI by Pim1 Kinase}

of Pim-1 has been shown to decrease infarct size and maintain contractility after myocardial infarction [2, 29], whereas Pim-1 knock out displayed a significant prolongation of calcium decay and the sarcomeric relaxation period and this was accompanied by a decrease in sarcoendoplasmic reticulum $\mathrm{Ca}^{2+} \mathrm{ATP}$-ase (SERCA) and sodium-calcium exchanger (NCX) expression [8]. However, it is still unknown whether Pim-1 regulates cardiac myofilament function by posttranslational modulation of sarcomere proteins. Indeed, our coimmunoprecipitation and colocalization assays demonstrated a direct binding of Pim1 with cTnI in cardiac cells, which led us to further investigate whether Pim-1 regulates myofilament activity through phosphorylating cTnI. In vitro phosphorylation assays showed that cTnI was robustly phosphorylated by Pim-1 in a time and dose dependent manner. To our knowledge, this is the first evidence demonstrating cTnI as a natural substrate of Pim-1 kinase in cardiomyocytes. Furthermore, by applying a site directed mutagenesis strategy and mass spectrometry analysis, we demonstrate that Pim-1 phosphorylates cTnI primarily at Ser23/24 and at Ser150. Furthermore, our in vitro study shows that Pim-1 preferentially phosphorylates cTnI at Ser23/24, and the precise mechanism underlying this process is unknown. We speculate that once Pim-1 binds to cTnI, it will cause a conformational change of cTnI that favors the binding of Pim-1 to the site of Ser23/24. It is well established that phosphorylation of cTnI at different sites results in different myofilament function [34]. For example, both PKA and PKD have been shown to phosphorylate cTnI at Ser23/24, which resulted in a reduction of $\mathrm{Ca}^{2+}$ sensitivity and acceleration of relaxation and crossbridge cycle kinetics [13-15]. In contrast, p21-activated kinase (PAK), which phosphorylates cTnI at Ser150, has been shown to increase $\mathrm{Ca}^{2+}$ sensitivity [19]. Furthermore, AMPK, which causes a cTnI phosphorylation predominantly at Ser150 as compared to Ser23/24, has been shown to increase myofilament $\mathrm{Ca}^{2+}$ sensitivity and prolong cardiac relaxation $[21,22]$. In the present study, we herein provided a novel phosphorylation pattern of cTnI as regulated by cardioprotective Pim-1 kinase in the heart. Indeed, our biochemical assays showed that compared to Ser150, Pim-1 preferentially phosphorylates cTnI at Ser23/24, leading to a reduction of myofilament $\mathrm{Ca}^{2+}$ sensitivity. It should be noted that the change of cardiac myofilament $\mathrm{Ca}^{2+}$ sensitivity does not always correlate with the change of maximum force. For example, J van der Velden et al. reported that the maximum force was not significantly changed, but the $\mathrm{Ca}^{2+}$ sensitivity was significantly increased in end-stage failing hearts, which may be attributed to the altered phosphorylation of contractile proteins such as myosin light chain 2 (MLC-2) and cTnT [36]. In our study, we also found that in addition to cTnI, cTnT may also function as a substrate of Pim-1 in the heart, which may contribute to the reduced $\mathrm{Ca}^{2+}$ sensitivity and unchanged maximum force.

Insulin-like growth factor I (IGF-I) is an important growth factor for cell differentiation and proliferation [37]. In the heart, it has been shown to stimulate cardiac growth and increase contractile function [24, 25]. Moreover, cardiac specific overexpression of IGF-1 has been shown to reduce myofilament isometric tension and increase cTnI phosphorylation, through a yet unknown mechanism [38]. Recently, IGF-1 has been found to potently induce Pim-1 expression in cardiomyocytes [8]. In our study, we found that Pim-1 increases cTnI phosphorylation at Ser23/24 and Ser150 in a Pim-1- dependent manner in cardiomyocytes. In this regard, our studies provided a novel mechanism by which IGF-1 may exert some of its cardioprotective effects through regulation of cTnI phosphorylation and myofilament activity in the heart. Previously, Akt has been shown to be essentially involved in the induction of Pim-1 expression by IGF-1 in the heart [8]. Consistent with this finding [8], treatment of cardiomyocytes with AKT inhibitor LY294002 markedly, but not completely, blocked IGF-1induced cTnI phosphorylation, indicating that other molecular pathways may be involved in the IGF-1-induced Pim-1 expression and cTnI phosphorylation in the heart, which warrants further investigation. Indeed, in a diabetic cardiomyopathy model, it has been shown that the changes in myocardial pAkt and Pim-1 levels were not synchronous, with Pim-1 starting to decrease earlier than pAkt [39]. At this point, the molecular mechanism(s) responsible for Pim-1 downregulation in DCM remains elusive. Decreased phosphorylation of STAT3 and increased expression of protein phosphatase 2A (PP2A), have been reported to mainly 


\section{Cellular Physiology Cell Physiol Biochem 2018;45:2174-2186 $\begin{array}{lll}\text { DOI: 10.1159/000488161 } & \text { and Biochemistry } \\ \text { Published onlne: Varch 15, } 2018 & \begin{array}{l}\text { O 2018 The Author(s). Published by S. Karger AG, Basel } \\ \text { www.karger.com/cpb }\end{array}\end{array}$ \\ Zhu et al.: Phosphorylation of cTnI by Pim1 Kinase}

contribute the regulation of Pim-1 expression at transcriptional and posttranslational levels in the diabetic hearts $[7,39]$.

It is well established that diastolic dysfunction is the most prominent defect of diabetic cardiomyopathy, which is characterized by decreased compliance, prolonged myocardial relaxation, and altered intracellular $\mathrm{Ca}^{2+}$ homeostasis [40]. In streptozotocin (STZ) induced diabetic cardiomyopathy, reduced SERCA2a expression is still not sufficient to explain the contractile deficit [41]. In this study, we found that Pim-1 expression was significantly reduced in diabetic hearts, which is consistent with previous published studies [39]. Moreover, this reduction was accompanied by decreased phosphorylation levels of Ser23/24 and Ser150, suggesting that Pim-1 may represent an important upstream kinase responsible for modulating cTnI phosphorylation in diabetic cardiomyopathy. Indeed, several studies have shown that IGF-1 levels are significant reduced under diabetic conditions [42-44]. These results suggest that preservation of IGF-1/Pim-1 pathway in the heart may represent a novel therapeutic strategy to prevent the development of diabetic cardiomyopathy.

\section{Conclusion}

In summary, we have shown that Pim-1 is a novel kinase that interacts with cTnI in cardiomyocytes. This interaction is relatively specific, as it causes cTnI phosphorylation; it is functional, as it leads to a reduction of myofilament $\mathrm{Ca}^{2+}$ sensitivity; and it is physiological, as it may mediate the cardioprotective effects of IGF-1 on cardiomyocytes. These findings suggest that Pim-1 may be an important therapeutic target for promoting cardiac muscle contractility under various pathophysiological conditions, such as diabetic cardiomyopathy and heart failure.

\section{Acknowledgements}

This work was supported by the U.S. National Institutes of Health (R01HL103869 and R01GM123047), the AHA established investigator award (16EIA27710023), and grants from the Chinese Natural Science Foundation No. 81370418 to JS, No. 81100197 to NZ, No. 81470406 to SH, and No. 30971231 and No. 81670342 to YQ. We are grateful to Dr. Sachio Morimoto from Kyushu University Graduate School of Medicine in Japan for the assistance of myofilament functional assays.

\section{Disclosure Statement}

The authors declare that they have no Disclosure Statement.

\section{References}

1 Bachmann M, Moroy T: The serine/threonine kinase Pim-1. Int J Biochem Cell Biol 2005;37:726-730.

-2 Fischer KM, Cottage CT, Konstandin MH, Volkers M, Khan M, Sussman MA: Pim-1 kinase inhibits pathological injury by promoting cardioprotective signaling. J Mol Cell Cardiol 2011;51:554-558.

-3 Sussman MA, Volkers M, Fischer K, Bailey B, Cottage CT, Din S, Gude N, Avitabile D, Alvarez R, Sundararaman B, Quijada P, Mason M, Konstandin MH, Malhowski A, Cheng Z, Khan M, McGregor M: Myocardial AKT: the omnipresent nexus. Physiol Rev 2011;91:1023-1070.

-4 Borillo GA, Mason M, Quijada P, Volkers M, Cottage C, McGregor M, Din S, Fischer K, Gude N, Avitabile D, Barlow S, Alvarez R, Truffa S, Whittaker R, Glassy MS, Gustafsson AB, Miyamoto S, Glembotski CC, Gottlieb RA, Brown JH, Sussman MA: Pim-1 kinase protects mitochondrial integrity in cardiomyocytes. Circ Res 2010;106:1265-1274. 


\section{Cellular Physiology Cell Physiol Biochem 2018;45:2174-2186 \begin{tabular}{ll|l} 
and Biochemistry & $\begin{array}{l}\text { DOI: 10.1159/000488161 } \\
\text { Published online: March 15, } 2018\end{array}$ & $\begin{array}{l}\text { (c) } 2018 \text { The Author(s). Published by S. Karger AG, Basel } \\
\text { www.karger.com/cpb }\end{array}$
\end{tabular}

5 Mohsin S, Khan M, Toko H, Bailey B, Cottage CT, Wallach K, Nag D, Lee A, Siddiqi S, Lan F, Fischer KM, Gude N, Quijada P, Avitabile D, Truffa S, Collins B, Dembitsky W, Wu JC, Sussman MA: Human cardiac progenitor cells engineered with Pim-I kinase enhance myocardial repair. J Am Coll Cardiol 2012;60:1278-1287. Quijada P, Toko H, Fischer KM, Bailey B, Reilly P, Hunt KD, Gude NA, Avitabile D, Sussman MA: Preservation of myocardial structure is enhanced by pim-1 engineering of bone marrow cells. Circ Res 2012;111:77-86.

7 Katare R, Caporali A, Zentilin L, Avolio E, Sala-Newby G, Oikawa A, Cesselli D, Beltrami AP, Giacca M, Emanueli C, Madeddu P: Intravenous gene therapy with PIM-1 via a cardiotropic viral vector halts the progression of diabetic cardiomyopathy through promotion of prosurvival signaling. Circ Res 2011;108:1238-1251.

8 Muraski JA, Rota M, Misao Y, Fransioli J, Cottage C, Gude N, Esposito G, Delucchi F, Arcarese M, Alvarez R, Siddiqi S, Emmanuel GN, Wu W, Fischer K, Martindale JJ, Glembotski CC, Leri A, Kajstura J, Magnuson N, Berns A, Beretta RM, Houser SR, Schaefer EM, Anversa P, Sussman MA: Pim-1 regulates cardiomyocyte survival downstream of Akt. Nat Med 2007;13:1467-1475.

-9 Solaro RJ, Varghese J, Marian AJ, Chandra M: Molecular mechanisms of cardiac myofilament activation: modulation by pH and a troponin T mutant R92Q. Basic Res Cardiol 2002;97 Suppl 1:I102-110.

10 Streng AS, de Boer D, van der Velden J, van Dieijen-Visser MP, Wodzig WK: Posttranslational modifications of cardiac troponin T: an overview. J Mol Cell Cardiol 2013;63:47-56.

11 Solaro RJ, Henze M, Kobayashi T: Integration of troponin I phosphorylation with cardiac regulatory networks. Circ Res 2013;112:355-366.

12 Metzger JM, Westfall MV: Covalent and noncovalent modification of thin filament action: the essential role of troponin in cardiac muscle regulation. Circ Res 2004;94:146-158.

13 Kentish JC, McCloskey DT, Layland J, Palmer S, Leiden JM, Martin AF, Solaro RJ: Phosphorylation of troponin I by protein kinase A accelerates relaxation and crossbridge cycle kinetics in mouse ventricular muscle. Circ Res 2001;88:1059-1065.

14 Haworth RS, Cuello F, Herron TJ, Franzen G, Kentish JC, Gautel M, Avkiran M: Protein kinase D is a novel mediator of cardiac troponin I phosphorylation and regulates myofilament function. Circ Res 2004;95:1091-1099.

15 Cuello F, Bardswell SC, Haworth RS, Yin X, Lutz S, Wieland T, Mayr M, Kentish JC, Avkiran M: Protein kinase D selectively targets cardiac troponin I and regulates myofilament $\mathrm{Ca} 2+$ sensitivity in ventricular myocytes. Circ Res 2007;100:864-873.

16 Perry SV: Troponin I: inhibitor or facilitator. Mol Cell Biochem 1999;190:9-32.

17 Burkart EM, Sumandea MP, Kobayashi T, Nili M, Martin AF, Homsher E, Solaro RJ: Phosphorylation or glutamic acid substitution at protein kinase $\mathrm{C}$ sites on cardiac troponin I differentially depress myofilament tension and shortening velocity. J Biol Chem 2003;278:11265-11272.

18 Sakthivel S, Finley NL, Rosevear PR, Lorenz JN, Gulick J, Kim S, VanBuren P, Martin LA, Robbins J: In vivo and in vitro analysis of cardiac troponin I phosphorylation. J Biol Chem 2005;280:703-714.

19 Buscemi N, Foster DB, Neverova I, Van Eyk JE: p21-activated kinase increases the calcium sensitivity of rat triton-skinned cardiac muscle fiber bundles via a mechanism potentially involving novel phosphorylation of troponin I. Circ Res 2002;91:509-516.

20 Chen S, Zhu P, Guo HM, Solis RS, Wang Y, Ma Y, Wang J, Gao J, Chen JM, Ge Y, Zhuang J, Li J: Alpha1 catalytic subunit of AMPK modulates contractile function of cardiomyocytes through phosphorylation of troponin I. Life Sci 2014;98:75-82.

21 Oliveira SM, Zhang YH, Solis RS, Isackson H, Bellahcene M, Yavari A, Pinter K, Davies JK, Ge Y, Ashrafian H, Walker JW, Carling D, Watkins H, Casadei B, Redwood C: AMP-activated protein kinase phosphorylates cardiac troponin I and alters contractility of murine ventricular myocytes. Circ Res 2012;110:1192-1201.

22 Nixon BR, Thawornkaiwong A, Jin J, Brundage EA, Little SC, Davis JP, Solaro RJ, Biesiadecki BJ: AMPactivated protein kinase phosphorylates cardiac troponin I at Ser-150 to increase myofilament calcium sensitivity and blunt PKA-dependent function. J Biol Chem 2012;287:19136-19147.

23 Zhang P, Kirk JA, Ji W, dos Remedios CG, Kass DA, Van Eyk JE, Murphy AM: Multiple reaction monitoring to identify site-specific troponin I phosphorylated residues in the failing human heart. Circulation 2012;126:1828-1837.

-24 Ren J, Samson WK, Sowers JR: Insulin-like growth factor I as a cardiac hormone: physiological and pathophysiological implications in heart disease. J Mol Cell Cardiol 1999;31:2049-2061.

-25 Samarel AM: IGF-1 Overexpression rescues the failing heart. Circ Res 2002;90:631-633. 


\section{Cellular Physiology Cell Physiol Biochem 2018;45:2174-2186 \begin{tabular}{l|l|l}
\hline and Biochemistry 10.1159/000488161 & $\begin{array}{l}\text { C) } 2018 \text { The Author(s). Published by S. Karger AG, Basel } \\
\text { www.karger.com/cpb }\end{array}$ \\
\hline
\end{tabular}

26 Kobayashi K, Forte TM, Taniguchi S, Ishida BY, Oka K, Chan L: The db/db mouse, a model for diabetic dyslipidemia: molecular characterization and effects of Western diet feeding. Metabolism 2000;49:22-31.

27 Yan G, Qin Q, Yi B, Chuprun K, Sun H, Huang S, Sun J: Protein-L-isoaspartate (D-aspartate) O-methyltransferase protects cardiomyocytes against hypoxia induced apoptosis through inhibiting proapoptotic kinase Mst1. Int J Cardiol 2013;168:3291-3299.

-28 You B, Yan G, Zhang Z, Yan L, Li J, Ge Q, Jin JP, Sun J: Phosphorylation of cardiac troponin I by mammalian sterile 20-like kinase 1. Biochem J 2009;418:93-101.

-29 Kulandavelu S, Karantalis V, Fritsch J, Hatzistergos KE, Loescher VY, McCall F, Wang B, Bagno L, Golpanian S, Wolf A, Grenet J, Williams A, Kupin A, Rosenfeld A, Mohsin S, Sussman MA, Morales A, Balkan W, Hare JM: Pim1 Kinase Overexpression Enhances ckit+ Cardiac Stem Cell Cardiac Repair Following Myocardial Infarction in Swine. J Am Coll Cardiol 2016;68:2454-2464.

30 Chen M, Yi B, Zhu N, Wei X, Zhang GX, Huang S, Sun J: Pim1 kinase promotes angiogenesis through phosphorylation of endothelial nitric oxide synthase at Ser-633. Cardiovasc Res 2016;109:141-150.

-31 Buchanan J, Mazumder PK, Hu P, Chakrabarti G, Roberts MW, Yun UJ, Cooksey RC, Litwin SE, Abel ED: Reduced cardiac efficiency and altered substrate metabolism precedes the onset of hyperglycemia and contractile dysfunction in two mouse models of insulin resistance and obesity. Endocrinology 2005;146:5341-5349.

-32 Van den Bergh A, Flameng W, Herijgers P: Type II diabetic mice exhibit contractile dysfunction but maintain cardiac output by favourable loading conditions. Eur J Heart Fail 2006;8:777-783.

-33 Moore A, Shindikar A, Fomison-Nurse I, Riu F, Munasinghe PE, Ram TP, Saxena P, Coffey S, Bunton RW, Galvin IF, Williams MJ, Emanueli C, Madeddu P, Katare R: Rapid onset of cardiomyopathy in STZ-induced female diabetic mice involves the downregulation of pro-survival Pim-1. Cardiovasc Diabetol 2014;13:68.

-34 Messer AE, Marston SB: Investigating the role of uncoupling of troponin I phosphorylation from changes in myofibrillar $\mathrm{Ca}(2+)$-sensitivity in the pathogenesis of cardiomyopathy. Front Physiol 2014;5:315.

35 Solaro RJ, Kobayashi T: Protein phosphorylation and signal transduction in cardiac thin filaments. J Biol Chem 2011;286:9935-9940.

36 van Der Velden J, Klein LJ, Zaremba R, Boontje NM, Huybregts MA, Stooker W, Eijsman L, de Jong JW, Visser CA, Visser FC, Stienen GJ: Effects of calcium, inorganic phosphate, and pH on isometric force in single skinned cardiomyocytes from donor and failing human hearts. Circulation 2001;104:1140-1146.

37 Delafontaine P: Insulin-like growth factor I and its binding proteins in the cardiovascular system. Cardiovasc Res 1995;30:825-834.

-38 Redaelli G, Malhotra A, Li B, Li P, Sonnenblick EH, Hofmann PA, Anversa P: Effects of constitutive overexpression of insulin-like growth factor-1 on the mechanical characteristics and molecular properties of ventricular myocytes. Circ Res 1998;82:594-603.

-39 Katare RG, Caporali A, Oikawa A, Meloni M, Emanueli C, Madeddu P: Vitamin B1 analog benfotiamine prevents diabetes-induced diastolic dysfunction and heart failure through Akt/Pim-1-mediated survival pathway. Circ Heart Fail 2010;3:294-305.

40 Ward ML, Crossman DJ: Mechanisms underlying the impaired contractility of diabetic cardiomyopathy. World J Cardiol 2014;6:577-584.

-41 Zhang L, Cannell MB, Phillips AR, Cooper GJ, Ward ML: Altered calcium homeostasis does not explain the contractile deficit of diabetic cardiomyopathy. Diabetes 2008;57:2158-2166.

42 Segev Y, Eshet R, Yakir O, Haim N, Phillip M, Landau D: Systemic and renal growth hormone-IGF1 axis involvement in a mouse model of type 2 diabetes. Diabetologia 2007;50:1327-1334.

-43 Forsberg EA, Botusan IR, Wang J, Peters V, Ansurudeen I, Brismar K, Catrina SB: Carnosine decreases IGFBP1 production in db/db mice through suppression of HIF-1. J Endocrinol 2015;225:159-167.

-44 Sasaki T, Kuroko M, Sekine S, Matsui S, Kikuchi O, Susanti VY, Kobayashi M, Tanaka Y, Yuasa T, Kitamura T: Overexpression of insulin receptor partially improves obese and diabetic phenotypes in $\mathrm{db} / \mathrm{db}$ mice. Endocr J 2015;62:787-796. 